\title{
Carbon dioxide/methanol conversion cycle based on cascade enzymatic reactions supported on superparamagnetic nanoparticles
}

\author{
CATERINA G.C. MARQUES NETTO ${ }^{1}$, LEANDRO H. ANDRADE ${ }^{2}$ and HENRIQUE E. TOMA \\ ${ }^{1}$ Metalloenzymes and Mimetics Laboratory, Departamento de Química, Universidade Federal de \\ São Carlos, Rodovia Washington Luis, s/n, Km 235, 13565-905 São Carlos, SP, Brazil \\ ${ }^{2}$ Fine Chemistry and Biocatalysis Lab, Instituto de Química, Universidade de São \\ Paulo, Av. Prof. Lineu Prestes, 748, 05508-000 São Paulo, SP, Brazil \\ ${ }^{3}$ Supramolecular NanotechLab, Instituto de Química, Universidade de São Paulo, \\ Av. Prof. Lineu Prestes, 748, 05508-000 São Paulo, SP, Brazil \\ Manuscript received on May 6, 2017; accepted for publication on June 1, 2017
}

\begin{abstract}
The conversion of carbon dioxide into important industrial feedstock is a subject of growing interest in modern society. A possible way to achieve this goal is by carrying out the $\mathrm{CO}_{2} /$ methanol cascade reaction, allowing the recycle of $\mathrm{CO}_{2}$ using either chemical catalysts or enzymes. Efficient and selective reactions can be performed by enzymes; however, due to their low stability, immobilization protocols are required to improve their performance. The cascade reaction to reduce carbon dioxide into methanol has been explored by the authors, using, sequentially, alcohol dehydrogenase (ADH), formaldehyde dehydrogenase (FalDH), and formate dehydrogenase $(\mathrm{FDH})$, powered by $\mathrm{NAD}^{+} / \mathrm{NADH}$ and glutamate dehydrogenase $(\mathrm{GDH})$ as the co-enzyme regenerating system. All the enzymes have been immobilized on functionalized magnetite nanoparticles, and their reactions investigated separately in order to establish the best performance conditions. Although the stepwise scheme led to only $2.3 \%$ yield of methanol per NADH; in a batch system under $\mathrm{CO}_{2}$ pressure, the combination of the four immobilized enzymes increased the methanol yield by 64 fold. The studies indicated a successful regeneration of NADH in situ, envisaging a real possibility of using immobilized enzymes to perform the cascade $\mathrm{CO}_{2}$-methanol reaction.
\end{abstract}

Key words: carbon dioxide, enzyme cascade-reaction, methanol production, superparamagnetic nanoparticles, enzymatic catalysis.

\section{INTRODUCTION}

\section{CARBON DIOXIDE-METHANOL CYCLE}

Biological evolution required the use of carbon dioxide as a carbon source to construct important

Correspondence to: Henrique Eisi Toma

E-mail: henetoma@iq.usp.br

* Contribution to the centenary of the Brazilian Academy of Sciences. natural building blocks, compelling the employment of natural catalysts,- the enzymes (Emsley 2011, Smith and Morowitz 2016). They are specific, efficient and essential for life on earth (Ermler 1998, Lehninger 2006), and participate in most of the biological pathways, including the Calvin cycle, reductive citric acid cycle, reductive acetylCoA route and dicarboxylate/4-hydroxybutyrate cycle. All such cycles depend on specific enzymatic 
systems (Buchanan and Arnon 1990, Fridlyand and Scheibe 1999, Ragsdale 1991, Ducat and Silver 2012, Shi et al. 2015).

Nowadays, carbon dioxide is perhaps the target molecule of mankind, and different technologies to perform the $\mathrm{CO}_{2}$-methanol cycle have been developed, including chemical (Ganesh 2014) and enzymatic routes (Sultana et al. 2016). The growing interest on $\mathrm{CO}_{2}$ transformation into important starting feedstock in the chemical industries has arisen due to the negative environmental prospects of fossil fuels use (Liu et al. 2015). For instance, carbon dioxide has been announced as one of the most important greenhouse gases responsible for global warming, and the use of fossil fuels resources (oil, natural gas, coal) has a negative impact on the environment due to high concentrations of carboncontaining products managed by the modern society. These prospects escalated the search of catalysts capable of converting renewable sources into industrial feedstock (Huff and Sanford 2011). In this sense, nature's catalysts are the best candidates for developing artificial biological routes toward carbon dioxide reduction (Shi et al. 2015).

The $\mathrm{CO}_{2}$-methanol catalytic cycle is perhaps the most important artificial biological route deserving investments, considering that $\mathrm{CO}_{2}$ recycling into methanol represents a renewable and environmental friendly alternative to the fossil fuels, providing a feedstock to the chemical industry. Encompassing the perspectives of artificial photosynthesis, this cycle can be performed by a cascade reaction involving the enzymes formate dehydrogenase (FDH), formaldehyde dehydrogenase (FalDH) and alcohol dehydrogenase (ADH). A fourth enzyme capable of reducing $\mathrm{NAD}^{+}$to $\mathrm{NADH}$, is also required for regenerating the system, providing a positive feedback (Luo et al. 2015, Cazelles et al. 2013, Sultana et al. 2016).

Despite the existing efforts in this area, the conversion of $\mathrm{CO}_{2}$ into methanol is still a big challenge, since it involves the transfer of 6-electrons and 6-protons in the whole process, whereas most typical catalytic systems produce only formic acid or $\mathrm{CO}$ in a 2-electron, 2-proton process, while very often stopping the reduction at this point (Shen et al. 2015, Sasayama et al. 2016). In multi-enzymatic systems, even when formate is reduced to formaldehyde, a further reduction to methanol in water is hindered by the equilibrium between formaldehyde and methane diol. This can limit the formaldehyde reduction to methanol, turning dehydration the rate-limiting step in the overall reaction (Ma et al. 2016). On the other hand, formaldehyde is an enzyme inhibitor, and its accumulation in the system is not desirable (Teng et al. 2001). Moreover, the $\mathrm{CO}_{2}$-methanol cycle can also be limited by the methanol concentration in solution, since it has been shown that at a molar ratio of methanol to total volume of reaction higher than 1.5 , the activity of some enzymes may be inhibited (Jeon and Yeom 2011).

\section{ENZYME IMMOBILIZATION}

Because of their specific molecular structures, enzymes are very dependent on the interaction with the substrate and cofactors, and their active or binding sites are very sensitive to the size, shape, charge and local hydrophobic/hydrophilic features (Yon et al. 1998). Their catalytic activity is related to the stabilization of the transition state involved in the reaction, and depends upon the specific interaction with the substrate, as proposed by Emil Fisher in 1894 (Fisher 1894) in terms of a rigid key-lock scheme. Another point of view has been described (Koshland 1958), considering a more flexible association, allowing discrete and reversible conformational changes of the enzyme (Koshland 1968, Thoma and Koshland 1960, Eisenmesser et al. 2002). In the absence of substrate, some enzymes can have an open form, but in its presence, a closed conformation is induced in order to prevent the substrate escape, 
thus enhancing the catalysis (Buchachenko and Kuznetsov 2008). Conditional factors, such as $\mathrm{pH}$, temperature and ionic strength, can promote enzyme conformational changes, improving or depleting the catalysis (Eichwald and Walleczek 1998, Joshi et al. 2000).

In mostindustrial applications, the fragile nature of enzymes requires the enzyme immobilization, or its physical confinement, but without blocking their catalytic activities. Enzyme immobilization may be accompanied by structural changes influencing its activity (Kim et al. 2006, Sharma et al. 2007, Ge et al. 2009). For this reason, immobilization requires a careful methodology optimization for keeping or eventually improving the enzyme activity, and also for increasing the stability and allowing recycling. It should be noticed that enzyme immobilization can also afford protection against autolysis, proteolysis and aggregation effects. Among other advantages, immobilization greatly simplifies the reactor design, and provides an effective way to stop the reaction, e. g. by removing the enzyme (Mateo et al. 2007).

Two main immobilization methodologies can be highlighted: the reversible and the irreversible one. Irreversible immobilization can prevent the enzyme leaching from the support, however it should be mentioned that when the activity is lost, the support should be discarded with the enzyme, whereas in the case of a reversible immobilization the regeneration of the support can be feasible. Covalent bonding between the enzyme and support is usually employed in the irreversible methodology. For instance, coupling reactions can be performed using reactive groups such as amines, carboxylates and thiols. Carboxylic groups can be activated with 1-ethyl3-(3-dimethylaminopropyl)carbodiimide, or EDC (Kondo and Fukuda 1997) in order to bind amines, yielding stable amide bonds linking the enzyme to the support (Bílková et al. 2002, Hong et al. 2007, Demirel et al. 2004, Demirel and Mutlu 2005, Zeng et al. 2006, Guo et al. 2003, Iman et al. 1992,
Pan et al. 2009). Amine groups can be linked by means of glutaraldehyde, forming imine bonds, which can further be reduced with $\mathrm{NaBH}_{4}$.

Reversible immobilization generally involves the direct adsorption of the enzyme to the support surface, by means of hydrogen bonding, van der Waals forces, electrostatic and hydrophobic interactions. Adsorption decreases the free energy by means of the entropic effect, but it is influenced by $\mathrm{pH}$, ionic strength, temperature and solvent polarity (Öztürk et al. 2007, Valdés-Solís et al. 2009). Metal chelation can also be employed for a reversible immobilization, by connecting specific groups on the support and enzymes based on their coordination to suitable metal ions such as $\mathrm{Cu}(\mathrm{II})$ or Ni(II) (Bayramoglu et al. 2010, Wang et al. 2007, Akgöl and Denizli 2004).

The optimization of the immobilization procedures also depends on the nature of the support. Among the several existing supports, a very special one is provided by superparamagnetic nanoparticles (Andrade et al. 2010, Andrade et al. 2016, Netto et al. 2013, Toma 2013, 2015). They exhibit very large magnetic moments, behaving as giant paramagnetic atoms. Their response to an applied magnetic field is very fast, without keeping any memory (hysteresis) due to their isotropic, nanometric structures. The particles also exhibit a large surface area and a high mass transference associated with their great mobility in solution. In addition, superparamagnetic nanoparticles can be easily recovered by using an external magnet, providing a simple and rather convenient enzyme recycling and processing strategy.

The most commonly employed magnetic support is magnetite, but maghemite, and some other ferrites can also be used in the immobilization of proteins. Magnetite has a particularly high saturation magnetization $\left(92 \mathrm{emu} \mathrm{g}^{-1}\right)$, but it should be noticed that when the particles are smaller than $8 \mathrm{~nm}$, it can be difficult to protect against 
oxidation in the normal atmosphere because of their very large area, yielding frequently a mixtures of oxides with smaller crystallinity and poor magnetization response. Although the direct use of freshly made magnetite as support is relatively common, surface modification should be pursued to control the interaction between the magnetic core and the environment, improving the stability and reactivity. One can say that for every particular enzyme there will be an ideal support, however, the best choice is actually very difficult to predict. In some cases, a large surface area may be the most important factor, however, it should be noticed that a high density of reactive groups with minimal steric hindrances will also facilitate and improve the association of the support with the enzyme.

In this review article we focused on enzymatic immobilization to perform the conversion of carbon dioxide to methanol by using a sequential reduction catalysis involving FDH, FalDH and ADH enzymes immobilized on magnetic nanoparticles, and GDH as the enzyme responsible for accomplishing the $\mathrm{NAD}^{+} / \mathrm{NADH}$ cycle. Our current methodology requires the immobilization of the enzymes on different types of support to perform the reaction. In this regard, it should be noticed that two main immobilization methodologies are possible: co-immobilization and sequential immobilization. A low product inhibition of the enzymes may be observed in coimmobilization systems due to the intermediates consumption in situ, but the overall yield of methanol will not necessarily be improved since formaldehyde reduction can be delayed by the slow reaction from the first enzyme. On the other hand, sequential immobilization allows the optimization of the system for each enzyme separately, and eventually, the reaction can proceed by increasing the $\mathrm{CO}_{2}$ pressure to overcome diffusion problems (Luo et al. 2015).
SINGLE IMMOBILIZATION OF $\mathrm{CO}_{2}$-METHANOL CYCLE ENZYMES ON SUPERPARAMAGNETIC NANOPARTICLES

Along the last five years we have performed the separate immobilization of the four enzymes involved in $\mathrm{CO}_{2}$-methanol cascade reaction, e $\mathrm{g}$. alcohol dehydrogenase(ADH) from Saccharomyces cerevisae (Netto et al. 2015a), formaldehyde dehydrogenase (FalDH) from Pseudomonas putida (Netto, Andrade and Toma 2015b), Formate dehydrogenase (FDH) from Candida boidinii (Netto et al. 2012) and glutamate dehydrogenase (GDH) from bovine liver (Netto et al. 2016), on magnetite nanoparticles. Such magnetic supports encompassed distinct functionalities for better accommodating and exploring the enzyme characteristics. In our case, the most effective surface modifiers were obtained with a) aminopropyl-triethoxysilane (MagNP-APTS), b) silica shell and aminopropyl-triethoxysilane (MagNP@SiO ${ }_{2}$-APTS) and c) glyoxyl-agarose (MagNP-APTS/Glyoxyl-Agarose), as illustrated in Figure 1.

In the case of amino functionalized supports, the enzyme immobilization has been performed using the amine-aldehyde cross-linking methodology in which APTS was bound to the enzyme via a glutaraldehyde reaction. Glyoxyl-agarose however, can be directly used to bind the enzyme.

After immobilization, the systems have been evaluated in terms of activity/stability for each support, in comparison with the free enzyme, by applying an external magnetic field, either to analyze the solution content or to remove the product and add new reactants in a recycle study. It has been shown that every enzyme has a specific preference for an immobilization support, presumably because of the different conformations achieved upon attachment to each support. For instance, FDH exhibited best performance when immobilized onto MagNPAPTS, achieving higher thermal stability $\left(60^{\circ} \mathrm{C}, \mathrm{pH}\right.$ 


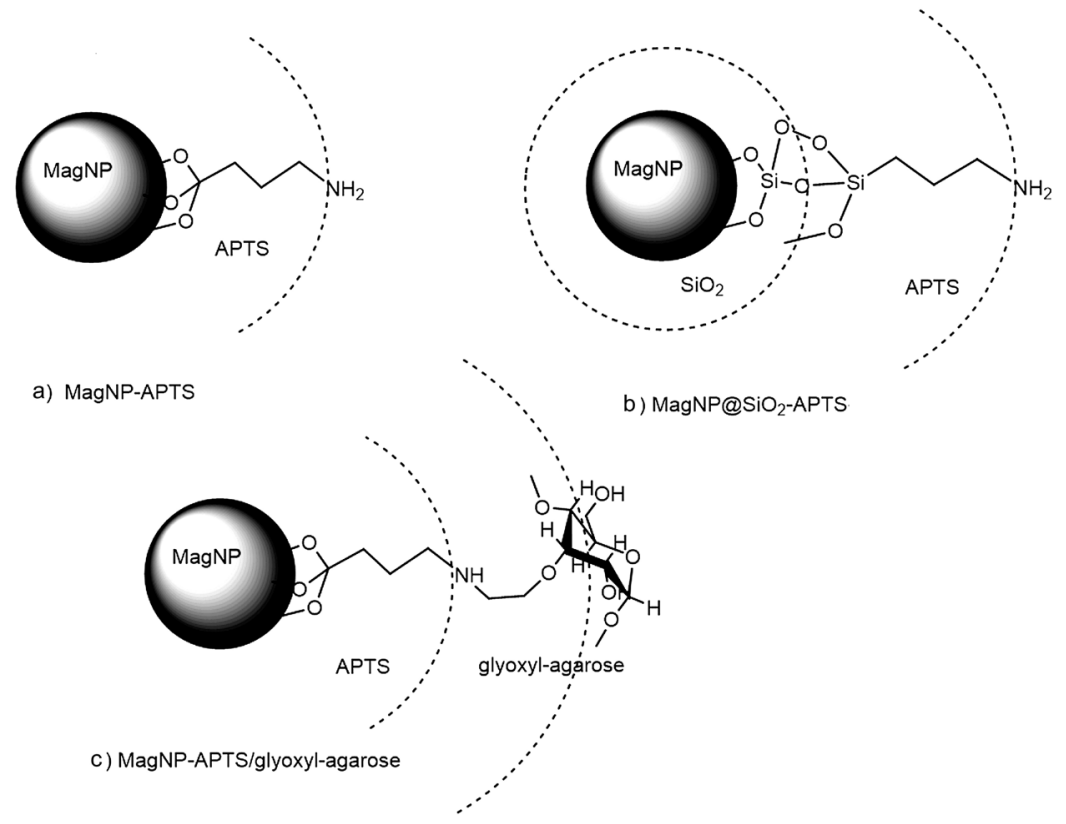

Figure 1 - Functionalized magnetic nanoparticles: a) MagNP-APTS, b) MagNP@ $\mathrm{SiO}_{2}$-APTS and c) MagNP-APTS/glyoxyl-agarose.

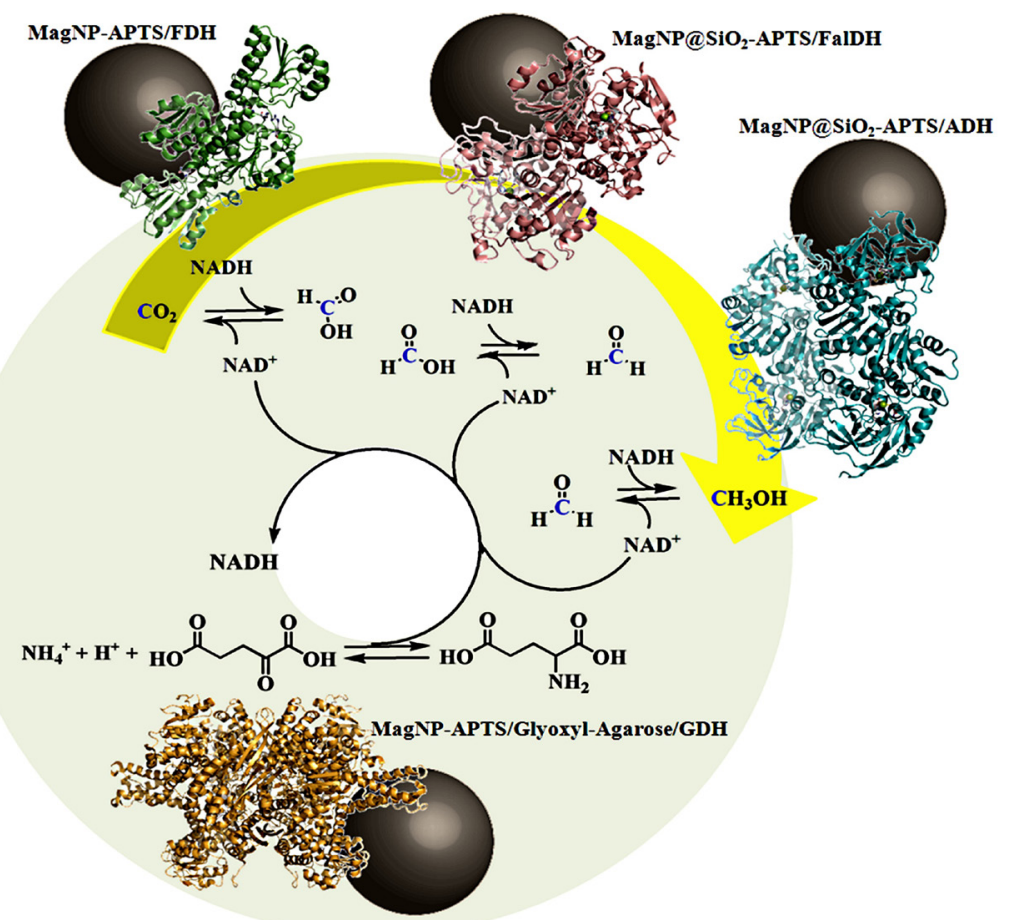

Figure 2 - $\mathrm{CO}_{2}$-methanol cycle using formate dehydrogenase (FDH) immobilized on MagNP-APTS, formaldehyde dehydrogenase (FalDH) and alcohol dehydrogenase (ADH) immobilized on MagNP@ $\mathrm{SiO}_{2}$-APTS and glutamate dehydrogenase (GDH) immobilized on MagNP-APTS/Glyoxyl-Agarose. The MagNP-APTS/GlyoxylAgarose/GDH system was used as a NADH regenerator. 
7.5) and good recyclability in relation to the other supports, or to the free enzyme (Netto et al. 2012). FalDH and ADH, on the other hand, exhibited best performance when immobilized onto MagNP@ $\mathrm{SiO}_{2}$-APTS, achieving higher scores for at their optimum $\mathrm{pHs}$ and temperatures, in relation to the respective free enzymes (Netto et al. 2015a). For both enzymes (FalDH and ADH) the influence of the iron couple, [Fe(II)/Fe(III)], from the magnetic nanoparticles core could be a limiting factor, arising from the possible conformation changes induced by the interaction with such metal ions, or to the redox interference in the electron transfer process (Netto et al. 2011, 2015a).

However, in the case of the glutamate dehydrogenase (GDH) enzyme, which is a hexameric protein, the best performance has been observed with the MagNP-APTS/Glyoxyl-Agarose support, allowing a higher thermal stability $\left(50^{\circ} \mathrm{C}\right.$, $\mathrm{pH}$ 7.5) and recyclability (Netto et al. 2016). Curiously, for this enzyme, the MagNP-APTS support seems to favor its unfolding, promoting an abnormal allosterism in presence of ADP, ATP and GTP. The influence of some iron coordination to the enzyme amino acids may also be possible in this case, by the lack of the silica coating, generating less stable enzymatic systems.

The comparison of the active sites of the enzymes showed that FalDH and ADH are metalloenzymes bearing a zinc coordination system involving at least one cysteine residue, as can be seen in Figure 3a and 3b. Cysteine is a key catalytic component for these enzymes and its oxidation can lead to metal release and enzyme inhibition, as already observed for ADH (Giles et al. 2003, Bühner and Sund 1969). Taken into account that the cysteine redox potential in biological systems is between $-270 \mathrm{mV}$ and $-125 \mathrm{mV}$ (Jocelyn 1967) and that the $\mathrm{Fe}(\mathrm{III}) / \mathrm{Fe}(\mathrm{II})$ redox potential is 771 $\mathrm{mV}$, it is plausible that when the surface iron ions become accessible, they can induce the oxidization of cysteine at the active site, inhibiting the enzyme activity. In contrast to the ADH and FalDH enzymes, FDH and GDH are not metal or cysteine dependent (Figure 3c and 3d), thus explaining why MagNP-APTS is a good support for FDH.

Another relevant point to mention is the ensamble of probable states in the intrinsic disorder theory (Netto et al. 2016). This theory is guided by entropic contributions to understand the protein dynamics, such as local unfolding, in order to achieve thermodynamic stability (Luque and Freire 2000) (Dyson and Wright 2002). The immobilization behavior of GDH can be rationalized using this theory (Netto et al. 2016).

Agglomeration is another important point influencing the activity of immobilized enzymes. A possible influence can be the prevention of the dissociation of multimeric enzymes and the contact between the enzyme and its possible inhibitors; however, on the other hand, it can also affect the diffusion of substrate to the active sites, imparting negatively the catalysis. Depending on their nature, substrate, inhibitors or products can be attracted or repelled by the agglomerates, perturbing the immediate vicinity of the enzyme (Roig et al. 1987). In our particular case, the supports used in the immobilization protocols bear amine groups (mostly in protonated form), and in this way they are prone to attract $\mathrm{CO}_{2}$, formaldehyde, methanol and formate species, enhancing the affinity towards the enzyme.

\section{MERGING THE IMMOBILIZED ENZYMES IN CATALYSIS}

Before setting the four immobilized enzymes together in a batch reaction, the best immobilization protocols for each specific enzyme should be previously investigated. Accordingly, the following binary or bi-enzymatic systems have been carefully evaluated: A) MagNP-APTS/FDH:MagNP-APTS/ Glyoxyl-Agarose/GDH; B) MagNP@SiO FalDH:MagNP-APTS/Glyoxyl-Agarose/GDH and C) MagNP@SiO 2 -APTS/ADH:MagNP-APTS/ 
a
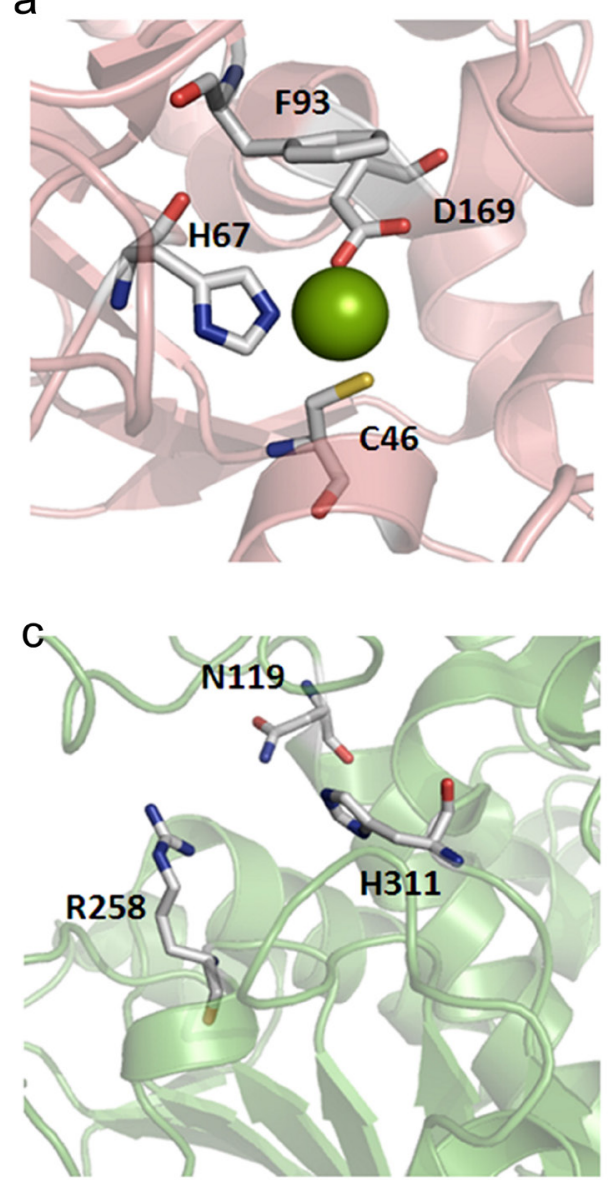

b

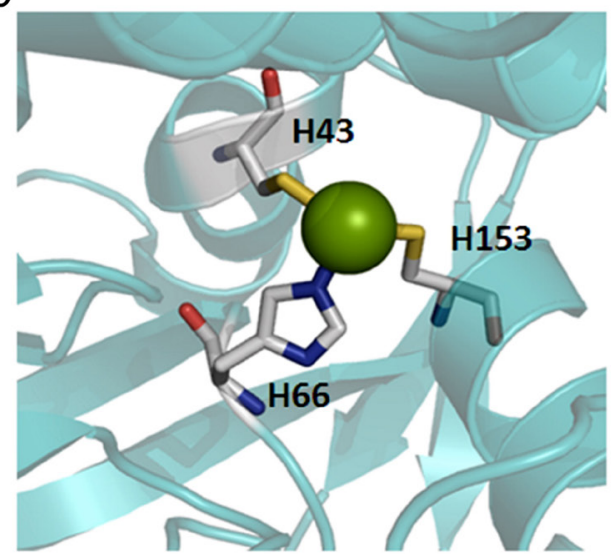

d

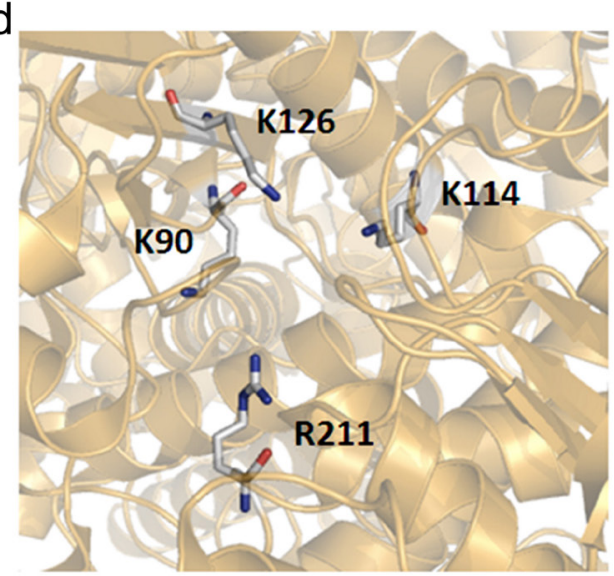

Figure 3 - Representation of the active sites for the $\mathrm{CO}_{2}$-methanol cycle enzymes: (a) FalDH, (b) $\mathrm{ADH}$, (c) FDH and (d) GDH. The green spheres represent $\mathrm{Zn}^{2+}$ ions.

Glyoxyl-Agarose/GDH. This strategy is important to evaluate the influence and compatibility of the $\mathrm{NAD}^{+} / \mathrm{NADH}$ regeneration system with respect to the immobilized enzymes. In this way, it was found that the three investigated binary enzymatic systems are compatible with the MagNP-APTS/ Glyoxyl-Agarose/GDH system employed for $\mathrm{NAD}^{+} / \mathrm{NADH}$ regeneration, showing maximum reaction yields up to $2 \mathrm{~h}$.

For illustration purposes, only the binary MagNP-APTS/FDH:MagNP-APTS/GlyoxylAgarose/GDH system will be depicted here. In this system, the amount of a-ketoglutarate formed during the $\mathrm{CO}_{2}$ reduction to formic acid has been evaluated by a colorimetric ninhydrin assay.
Different reaction $\mathrm{pHs}$ and temperatures have been investigated for this bi-enzymatic system and the best reaction conditions were pH $6.8(0.1 \mathrm{M}$ phosphate buffer) and $25^{\circ} \mathrm{C}$. Under such conditions, MagNP-APST/FDH system can accomplish its first cycle, giving $\mathrm{NAD}^{+}$, in 10 minutes, providing the substrate for MagNP-APTS/Glyoxyl-Agarose/ GDH in order to regenerate NADH. It has been bound that $\mathrm{NAD}^{+}$actually accumulates during the first 10 minutes of reaction (Figure 4), whereas NADH synthesis requires additional 20 minutes to reach completion. Similar performance has been observed for the other bi-enzymatic systems. It should to mentioned that by the lack of the silica coating, exposed iron sites in the MagNP-APTS 
support could potentially destabilize GDH enzyme during the immobilization protocol, however this has not been observed. In addition, the MagNPAPTS/FDH system also did not inhibit the immobilized GDH enzume, thus ruling out any influence from the possible iron leaching from the nanoparticles to the environment.

Based on these studies, it was shown that the proposed $\mathrm{NAD}^{+} / \mathrm{NADH}$ recycling system is compatible with the FDH, $\mathrm{ADH}$ and FalDH immobilized enzymes. Their concerted performance, however, involving cascade reactions can be planned according to two different methodologies: sequential reaction (Figure 5a) and batch multienzymatic reaction (Figure 2). For the sequential reaction, a previous $\mathrm{CO}_{2}$ saturation of the buffer solution has been performed, but the overall methanol yield was $2.3 \%$ based on the NADH concentration. Such low yield could result from the $\mathrm{CO}_{2}$ loss during the reaction or from the enzyme inhibition induced by the formic acid or formaldehyde products.

The multienzymatic cascade batch reaction has been carried out in a pressure reactor, in order to prevent the $\mathrm{CO}_{2}$ loss. The observed yields, around $5.2 \mathrm{mmol}$ of methanol, corresponds to $147 \%$ based on NADH consumption (considering $3 \mathrm{~mol}$ of $\mathrm{NADH}$ are needed to obtain $1 \mathrm{~mol}$ of methanol). The optimum conditions for the multienzymatic cascade reaction were $25^{\circ} \mathrm{C}, \mathrm{pH} 7.5,126 \mathrm{psi}$ of $\mathrm{CO}_{2}$ and 30 minutes of reaction (Figure 5b). It is interesting to note that when $11 \mathrm{mmol}$ of NADH was added to the batch system, $5.2 \mathrm{mmol}$ of methanol was generated from $\mathrm{CO}_{2}$. Comparatively, without applying any $\mathrm{NAD}^{+} / \mathrm{NADH}$ regeneration system, it would be required $15.6 \mathrm{mmol}$ of NADH. Therefore, a properly functioning $\mathrm{NAD}^{+} / \mathrm{NADH}$ regenerating system is esssential to improve the methanol yields. Another important aspect is that the multienzymatic system has been recycled four times, without considerable loss of its activity (Figure 5c).

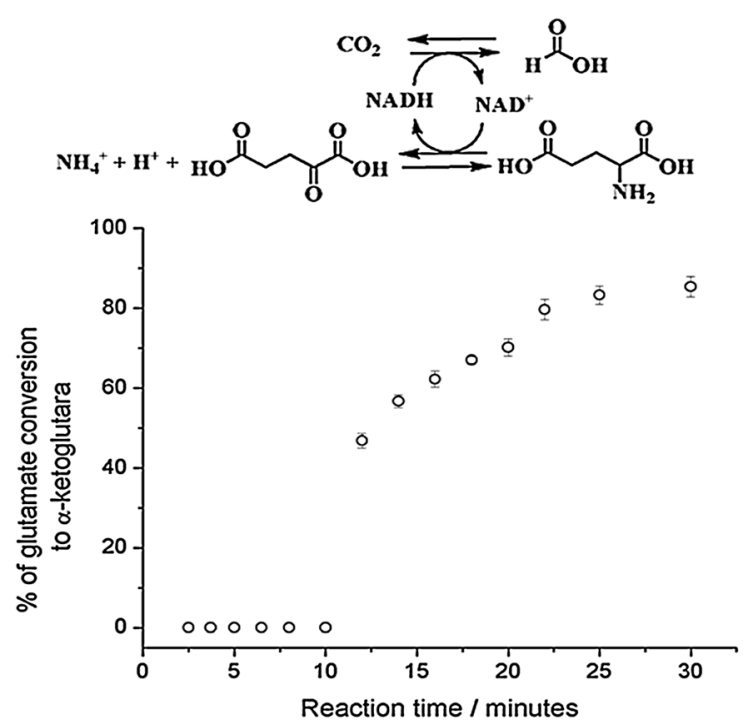

Figure 4 - Bi-enzymatic system involving MagNP-APTS/FDH and MagNP-APTS/Glyoxyl-Agarose/GDH. The reaction was evaluated by the conversion of glutamate to a-ketoglutarate by a colorimetric ninhydrin assay.

The electrocatalytical production of methanol from $\mathrm{CO}_{2}$ reported in the literature (Addo et al. 2011), using formate, aldehyde, and alcohol dehydrogenases coupled to a poly(neutral red) electrode, indicated that the conversion of carbon dioxide to formate is the slowest step in the enzyme cascade. As a matter of fact, in our system, if only FDH, FalDH and ADH were taken into consideration, the FDH reaction would also be the rate determining step, since as soon as formic acid was formed (evidenced by $\mathrm{NAD}^{+}$concentration), formaldehyde and methanol were also produced (Figure 5b). However, we believe the reaction would be more efficient if GDH could reduce $\mathrm{NAD}^{+}$faster than it was observed (Figure 5).

Unfortunately, the $\mathrm{NAD}^{+}$regenerating system based on immobilized GDH exhibits some drawbacks, such as the easy enzyme inactivation. As a matter of fact, a study employing GDH on polystyrene particles as support has achieved only $50 \%$ methanol conversion based on NADH (ElZahab et al. 2008). In spite of this, after 11 successive cycles, the cumulative yield of methanol was $127 \%$, 
a)
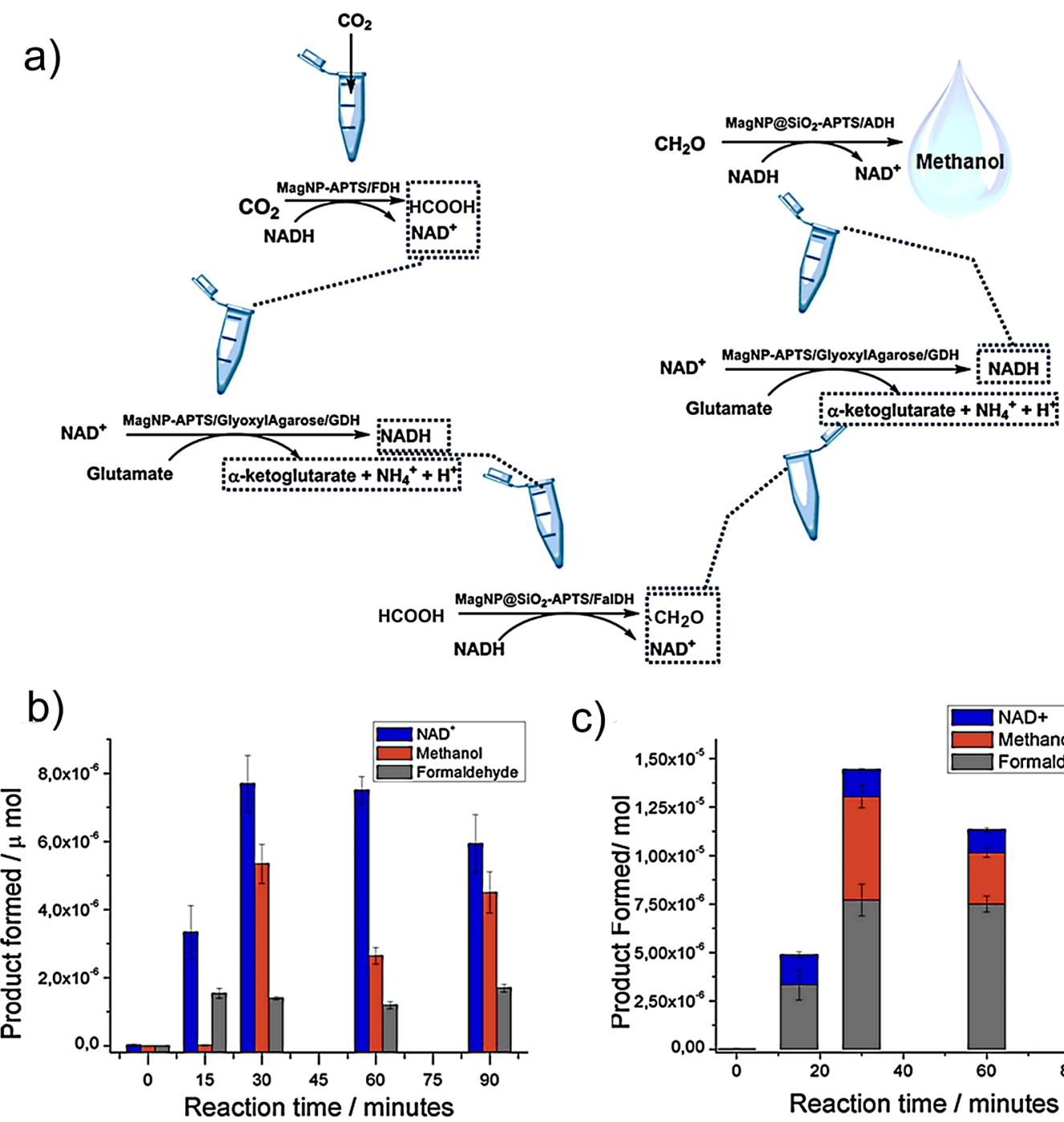

c)

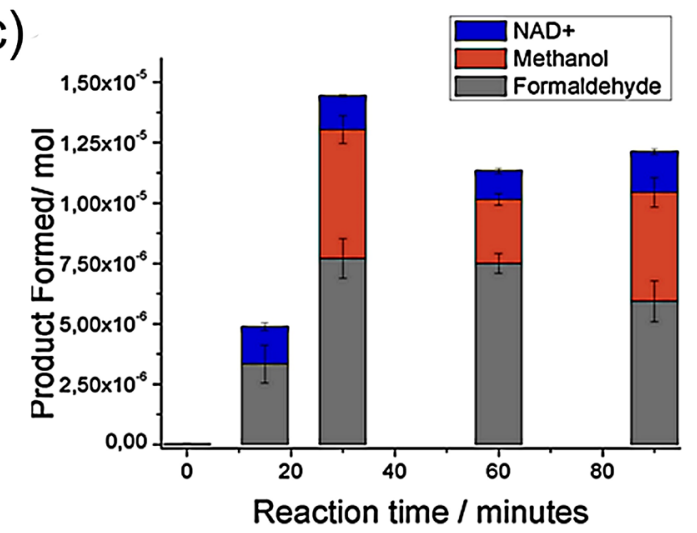

Figure 5 - (a) $\mathrm{CO}_{2}$-methanol sequential reaction; (b) cascade multienzymatic $\mathrm{CO}_{2}$-methanol reaction and the amount of formaldehyde, methanol and $\mathrm{NAD}^{+}$formed with reaction progress; (c) cascade multienzymatic $\mathrm{CO}_{2}$-methanol recycle at 25 psi, 30 minutes, $25^{\circ} \mathrm{C}$, $\mathrm{pH} 7.5$ (0.1M Tris- $\mathrm{HCl}$ buffer solution).

approaching the yields obtained in our laboratory. However, when the authors attempted to use $\mathrm{NAD}^{+}$ immobilization, the conversion dropped drastically to $5 \%$, indicating some diffusional limitation of the redox process in the system

Therefore, since the immobilized FDH, FalDH and $\mathrm{ADH}$ species exhibit outstanding stability and activity, the $\mathrm{NAD}^{+} / \mathrm{NADH}$ regeneration systems become a critical issue for improving the methanol synthesis. For this reason, several groups
(Kuwabata et al. 1994, Schlager et al. 2016, Singh et al. 2017, Dibenedetto et al. 2012) have been focusing their research at this front, using different strategies, such as a phosphite dehydrogenase (PTDH) system, a glycerol dehydrogenase system or a natural photosystem from spinach leaves (chloroplasts). The phosphite dehydrogenase system was the most efficient one, working at $\mathrm{pH} 7$ and yielding $4.3 \mathrm{mmol}\left(\mathrm{g}_{\text {commercial enzymatic powder }}\right)^{-1}$ after $3 \mathrm{~h}$ reaction (Cazelles et al. 2013). 
In addition, different immobilization strategies have also been described in the literature, such as enzyme encapsulation (Xu et al. 2006), but showing lower yields in comparison with our methodology. Encapsulation of dehydrogenase enzymes in silica matrix exhibited methanol yields between $16.8 \%$ and $43.8 \%$. If the gelation time was smaller than 60 seconds the methanol yield was much lower, as a result of the uneven distribution of the enzymes in the gel; however, at higher gelation times, 92\% yield of methanol could be achieved (Jiang et al. 2003).

The immobilization of the enzymes onto the magnetic nanoparticles does not suffer from the influence of gelation time, but it suffers from the influence of immobilization time, which is more correlated with the enzyme conformational changes than with the enzyme distribution on the support (Chang et al. 2008, Jiang 2004, Imai et al. 1986, Grazu et al. 2005, Wu et al. 2004, Wu and Lia 2008, Netto et al. 2012).

In general, three-dimensional structural changes and possible diffusion resistance become critical issues to be observed in enzymatic systems. For instance, it has been shown that after modifying the ADH enzyme with polyethylene glycol (PEG), the enzyme activity and stability were substantially improved. This may be due to the effect exerted by $\mathrm{PEG}$ on the enzyme, protecting from the surrounding environment, although it has also been proposed that the PEG-modified $\mathrm{ADH}$ is more flexible than unmodified ADH (Wu et al. 2004).

Supports such as titania (Sun et al. 2009) and nanofibers (Ji et al. 2015) have also been employed, achieving $60 \%$ and $103.2 \%$ yield of methanol production, respectively. In the last example, $\mathrm{a} \mathrm{CO}_{2}$ hydration enzyme was also coupled for increasing the overall conversion.

Several other methodologies describing the enzymatic reduction of $\mathrm{CO}_{2}$ to methanol can be found in the literature; however, none of them reports yields higher than $150 \%$. For instance, when methanol dehydrogenase (MDH) and formate dehydrogenase were used in the electrolysis of $\mathrm{CO}_{2}$ in a saturated buffer solution, the reported yield was only 45\% (Kuwabata et al. 1993). Some limitation in the $\mathrm{CO}_{2}$-methanol cycle has also been imputed to the formaldehyde accumulation at poisonous concentrations, influencing the other enzymatic systems.

Therefore, more efforts should be directed to the optimization of the artificial $\mathrm{CO}_{2}$-methanol conversion cycles, in order to enable their commercial use in the future. As a long-term goal, the immobilization strategy can also be extended to the production of molecules containing more carbon atoms, employing new appropriate enzymes, inspired on Nature's ability to generate more elaborate molecules rather than methanol.

\section{CONCLUSIONS}

Magnetic nanoparticles with different functionalization can be selectively employed for enzyme immobilization and applied to perform the $\mathrm{CO}_{2} /$ methanol conversion cycle. In particular FalDH and ADH enzymes, which are metal and cysteine dependent, seem to be sensitive to the iron exposure at the surface, requiring the use of a silica protecting coating on the magnetic nanoparticles. In contrast, FDH, which is not prone to redox interferences, can exhibit good activity and stability even in the absence of the silica coating. GHD, on the other hand, when in the immobilized form, showed a good compatibility with the FalDH, $\mathrm{ADH}$, and $\mathrm{FDH}$ enzymes, as a $\mathrm{NAD}^{+} / \mathrm{NADH}$ regenerating system. Unfortunately, however, the low conversion rates observed for this enzyme are yet a critical factor, decreasing the yields for the production of methanol from $\mathrm{CO}_{2}$. Fortunately, it has been shown that the overall reaction is not limited by the diffusion of the substrates, indicating that the enzyme immobilization procedure can be carried out effectively, even in separate. Actually, it 
becomes more effective than the co-immobilization strategy, allowing to explore conveniently the best enzyme performance associated with each specific support.

Although the multienzymatic batch cascade reaction has presented a good conversion rates of $\mathrm{CO}_{2}$ into methanol (147\%), there is still plenty room for improvement, including the exploration of more efficient $\mathrm{NAD}^{+} / \mathrm{NADH}$ recovering systems. At the present time, new promising methodologies are being pursued worldwide, with the hope of reaching a sustainable $\mathrm{CO}_{2} /$ methanol conversion technology.

\section{ACKNOWLEDGMENTS}

We thank Fundação de Amparo à Pesquisa do Estado de São Paulo (FAPESP) for the financial support (grants: 2008/10177-7, 2013/24725-4)

\section{REFERENCES}

ADDO PK, ARECHEDERRA RL, WAHEED A, SHOEMAKER JD, SLY WS AND MINTEER SD. 2011. Methanol Production via Bioelectrocatalytic Reduction of Carbon Dioxide: Role of Carbonic Anhydrase in Improving Electrode Performance. Electrochem SolidState Lett 14: E9-E13.

AKGÖL S AND DENIZLI A. 2004. Novel metal-chelate affinity sorbents for reversible use in catalase adsorption. $\mathrm{J}$ Mol Cat B Enzym 28: 7-14.

ANDRADE LH, REBELO LP, NETTO CGCM and TOMA HE. 2010. Kinetic resolution of a drug precursor by Burkholderia cepacia lipase immobilized by different methodologies on superparamagnetic nanoparticles. J Mol Cat B Enzym 66: 55-62.

ANDRADE MFC, PARUSSULO ALA, NETTO CGCM, ANDRADE LH AND TOMA HE. 2016. Lipase immobilized on polydopamine-coated magnetite nanoparticles for biodiesel production from soybean oil. Biodiesel Research J 10: 403-409.

BAYRAMOGLU G, YILMAZ GM AND ARICA MY. 2010. Reversible immobilization of laccase to poly(4vinylpyridine) grafted and $\mathrm{Cu}(\mathrm{II})$ chelated magnetic beads: Biodegradation of reactive dyes. Biores Technol 101: 6615-6621.

BÍLKOVÁ Z, SLOVÁKOVÁ M, HORÁK D, LENFELDC J AND CHURÁCEK J. 2002. Oriented immobilization of galactose oxidase to bead and magnetic bead cellulose and poly(HEMA-co-EDMA) and magnetic poly(HEMAco-EDMA) microspheres. J Chromatogr B 770: 177-181.

BUCHACHENKO AL AND KUZNETSOV DA. 2008. Magnetic Field Affects Enzymatic ATP Synthesis. J Am Chem Soc 130: 12868-12869.

BUCHANAN BB AND ARNON DI. 1990. A reverse KREBS cycle in photosynthesis: consensus at last. Photosynth Res 24: 47-53.

BÜHNER M AND HUND H. 1969. Yeast Alcohol Dehydrogenase: -SH Groups, Disulfide Groups, Quaternary Structure, and Reactivation by Reductive Cleavage of Disulfide Groups. Eur J Biochem 11: 73-80.

CAZELLES R, DRONE RJ, FAJULA F, ERSEN O, MOLDOVAN S AND GALARNEAU A. 2013. Reduction of $\mathrm{CO} 2$ to methanol by a polyenzymatic system encapsulated in phospholipids-silica nanocapsules. New J Chem 37: 3721-3730.

CHANG SW, SHAW JF, YANG KH, CHANG SF AND SHIEH CJ. 2008. Studies of optimum conditions for covalent immobilization of Candida rugosa lipase on poly(c-glutamic acid) by RSM. Biores Technology 99: 2800-2805.

DEMIREL D AND MUTLU DM. 2005. Performance of immobilized pectinex ultra SP-L on magnetic duolitepolystyrene composite particles. Part II: A magnetic fluidized bed reactor study. J Food Eng 70: 1-6.

DEMIREL D, ÖZDURAL AR AND MUTLU M. 2004. Performance of immobilized Pectinex Ultra SP-L on magnetic duolite-polystyrene composite particles Part I: a batch reactor study. J Food Eng 64: 417-421.

DIBENEDETTO AP, STUFANO P, MACYK, W, BARAN T, FRAGALE C, COSTA M AND ARESTA M. 2012. Hybrid Technologies for an Enhanced Carbon Recycling Based on the Enzymatic Reduction of $\mathrm{CO} 2$ to Methanol in Water: Chemical and Photochemical NADH Regeneration. ChemSusChem 5: 373-378.

DUCAT DC AND SILVER PA. 2012. Improving Carbon Fixation Pathways. Current Opinion in Chem Biol 16: 337-344.

DYSON HJ AND WRIGHT PE. 2002. Coupling of folding and binding for unstructured proteins. Current Opinion in Structural Biology 12: 54-60.

EICHWALD C AND WALLECZEK J. 1998. Magnetic field perturbations as a tool for controlling enzyme-regulated and oscillatory biochemical reactions. Biophys Chem 74: 209-224.

EISENMESSER EZ, BOSCO DA, AKKE M AND KERN D. 2002. Enzyme dynamics during catalysis. Science 295: $1520-1523$

El-ZAHAB B, DONNELLY D AND WANG P. 2008. Particletethered NADH for production of methanol from $\mathrm{CO} 2$ catalyzed by coimmobilized enzymes. Biotechnology and Bioengineering 99: 508-514. 
EMSLEY J. 2011. Nature's Building Blocks: An A-Z Guide to the Elements. Oxford University Press, New York.

ERMLER U, GRABARSE W, SHIMA S, GOUBEAUD M AND THAUER RK. 1998. Active sites of transitionmetal enzymes with a focus on nickel. Current Opinion in Structural Biology 8: 749-758.

FISHER E. 1894. Einfluss der Configuration auf die Wirkung der Enzyme. Berichte der Deutschen Chemischen Gesellschaft 27: 2985-2888.

FRIDLYAND LE AND SCHEIBE R. 1999. Regulation of the Calvin cycle for $\mathrm{CO}_{2}$ fixation as an example for general control mechanisms in metabolic cycles. Biosystems 51: 79-93.

GANESH I. 2014. Conversion of carbon dioxide into methanol - a potential liquid fuel: Fundamental challenges and opportunities. Renew Sustainable Energy Rev 31: 221-257.

GE J, LU D, LIU Z AND LIU ZX AND LIU Z. 2009. Recent advances in nanostructured biocatalysts. Biochem Eng $\mathrm{J}$ 44: 53-59.

GILES NM, WATTS AB, GILES GI, FRY FH, LITTLECHILD JAAND JACOB C. 2003. Metal and Redox Modulation of Cysteine Protein Function. Chem Biol 10: 677-693.

GRAZU V, ABIAN O, MATEO C, BATISTA-VIEIRA F, FERNANDEZ-LAFUENTE R AND GUISA JM. 2005. Stabilization of Enzymes by Multipoint Immobilization of Thiolated Proteins on New Epoxy-Thiol Supports. Biotechnol Bioeng 90: 597-605.

GUO Z, BAI S AND SUN Y. 2003. Preparation and characterization of immobilized lipase on magnetic hydrophobic microspheres. Enzyme MicrobTechnol 32: 776-782.

HONG J, XU D, GONG P, MA H, DONG L AND YAO S. 2007. Conjugation of enzyme on superparamagnetic nanogels covered with carboxyl groups. J Chromatogr B 850: 499-506.

HUFF CA AND SANFORD MS. 2011. Cascade Catalysis for the Homogeneous Hydrogenation of $\mathrm{CO} 2$ to Methanol. J Am Chem Soc 133: 18122-18125.

IMAI K, SHIOMI T, UCHIDA K AND MIYA M. 1986. Immobilization of Enzyme onto Poly(ethylene-Vinyl Alcohol) Membrane. Biotechnol Bioeng 28: 198-203.

IMAN M, ÇELEBI SS AND ÖZDURAL AR. 1992. Preparation of photooxidized magnetic polystyrene beads for enzyme immobilization. Reactiv Polym 17: 325-340.

JEON DJ AND YEOM SH. 2011. Comparison of methods for preventing methanol inhibition in enzymatic production of biodiesel. Korean J Chem Eng 28: 1420-1426.

JI X, SU Z, WANG P, MA G AND ZHANG S. 2015. Tethering of Nicotinamide Adenine Dinucleotide Inside Hollow Nanofibers for High-Yield Synthesis of Methanol from Carbon Dioxide Catalyzed by Coencapsulated Multienzymes. ACS Nano 9: 4600-4610.
JIANG Z, WU H, XU S AND HUANG S. 2003. Enzymatic Conversion of Carbon Dioxide to Methanol by Dehydrogenases Encapsulated in Sol-Gel Matrix. In Utilization of Greenhouse Gases. ACS Symposium Series 852: 212-218.

JIANG Z AND WU XS. 2004. Novel conversion of carbon dioxide to methanol catalyzed by sol-gel immobilized dehydrogenases. Stud Surf Sci Catal 153: 475-480.

JOCELYN PC. 1967. The Standard Redox Potential of Cysteine-Cystine from the Thiol-Disulphide Exchange Reaction with Glutathione and Lipoic Acid. European J Biochem 2: 327-330.

JOSHI MD, SIDHU G, BRAYER GD, WITHERS SG AND MCINTOSH LP. 2000. Hydrogen bonding and catalysis: a novel explanation for how a single amino acid substitution can change the $\mathrm{pH}$ optimum of a glycosidase. J Mol Biol 299: 255-279.

KIM J, GRATE JW AND WANG P. 2006. Nanostructures for enzyme stabilization. Chem Eng Sci. 61: 1017-1026.

KONDO A AND FUKUDA H. 1997. Preparation of thermosensitive magnetic hydrogel microspheres and application to enzyme immobilization. J Ferment Bioeng 84: 337-341.

KOSHLAND DE. 1968. The catalytic and regulatory properties of enzymes. Annu Rev Biochem 37: 359-364.

KOSHLAND DE. 1958. Application of a Theory of Enzyme Specificity to Protein Synthesis. Proc Natl Acad Sci USA 44: 98-101.

KUWABATAS, TSUDAR, NISHIDAKANDYONEYMAMA H. 1993. Electrochemical Conversion of Carbon Dioxide to Methanol with Use of Enzymes as Biocatalysts. Chemistry Lett 22: 1631-1634.

KUWABATA S, TSUDA R AND YONEYAMA H. 1994. Electrochemical conversion of carbon dioxide to methanol with the assistance of formate dehydrogenase and methanol dehydrogenase as biocatalysts. J Am Chem Soc 116: 5437-5443.

LEHNINGER AL. 2006. Principles of biochemistry, WH Freeman and Company, New York.

LIU Q, WU L, JACKSTELL R AND BELLER M. 2015. Using carbon dioxide as a building block in organic synthesis. Nat Commun 6: 5933-5934

LUQUE I AND FREIRE E. 2000. Structural Stability of Binding Sites: Consequences for binding affinity and allosteric effects. Proteins: Struct Funct Genet Suppl 4: 63-71.

LUO J, MEYER AS, MATEIU RV AND PINELO M. 2015. Cascade catalysis in membranes with enzyme immobilization for multi-enzymatic conversion of $\mathrm{CO} 2$ to methanol. New Biotechnol 32: 319-327.

MA K, YEHEZKELI O, PARK E AND CHA JN. 2016. Enzyme Mediated Increase in Methanol Production from Photoelectrochemical Cells and CO2. ACS Catal 6: 69826986. 
MATEO C, PALOMO JM, FERNANDEZ-LORENTE G, GUISAN JM AND FERNANDEZ-LAFUENTE R. 2007. Improvement of enzyme activity, stability and selectivity via immobilization techniques. Enzyme Microb Technol 40: 1451-1463.

NETTO CGCM, ANDRADE LH, FREITAS RS AND TOMA HE. 2015a. Association of Yeast Alcohol Dehydrogenase with Superparamagnetic Nanoparticles: Improving the Enzyme Stability and Performance. J Nanosci Nanotechnol 15: 9482-9487.

NETTO CGCM, ANDRADE LH AND TOMA HE. 2015b. Association of Pseudomonas putida formaldehyde dehydrogenase with superparamagnetic nanoparticles: an effective way of improving the enzyme stability, performance and recycling. New J Chem 39: 2162-2167.

NETTO CGCM, DASILVA DG, TOMA SH, ANDRADE LH, NAKAMURA M, ARAKI K AND TOMA HE. 2016. Bovine Glutamate Dehydrogenase Immobilization on Magnetic Nanoparticles : conformational changes and catalysis. RSC Adv 6: 12977-12992.

NETTO CGCM, NAKAMATSU EH, NETTO LES, NOVAK MA, ZUIN A, NAKAMURA M, ARAKI K, AND TOMA HE. 2011. Catalytic properties of thioredoxin immobilized on superparamagnetic nanoparticles. J Inorg Biochem 105: 738-744.

NETTO CGCM, NAKAMURA M, ANDRADE LH AND TOMA HE. 2012. Improving the catalytic activity of formate dehydrogenase from Candida boidinii by using magnetic nanoparticles. J Mol Catalysis B Enzym 84: 136143.

NETTO CGCM, TOMA HE AND ANDRADE LH. 2013. Superparamagnetic nanoparticles as versatile carriers and supporting materials for enzymes. J Mol Catalysis B Enzym 85-86: 71-92.

ÖZTÜRK N, AKGÖL S, ANSOY M AND DENIZLI A. 2007. Reversible adsorption of lipase on novel hydrophobic nanospheres. Sep Purif Technol 58: 83-88.

PAN C, HU B, LI W, SUN Y, YE H AND ZENG X. 2009. Novel and efficient method for immobilization and stabilization of $\beta$-d-galactosidase by covalent attachment onto magnetic $\mathrm{Fe}_{3} \mathrm{O}_{4}$-chitosan nanoparticles. J Mol Cat B Enzym 61: 208-213.

RAGSDALE SW. 1991. Enzymology of the acetyl-CoA pathway of $\mathrm{CO}_{2}$ fixation. Crit Rev Biochem Mol. Biol. 26: 261-300.

ROIG MG, ESTEVEZ FB, VELASCO FG AND CACHAZA JM. 1987. Evaluation of the Main Factors Determining the Mode of Action of Immobilized Enzymes. Biochem Ed 15: 33-41.

SASAYAMA AF, MOORE CE AND KUBIAK CP. 2016. Electronic effects on the catalytic disproportionation of formic acid to methanol by [CpIr(III)(R-bpy)Cl]Cl complexes. Dalton Transactions 45: 2436-2439.
SCHLAGER S, DUMITRU LM, HABERBAUER M, FUCHSBAUERA,NEUGEBAUERH, HIEMETSBERGER D, WAGNER A, PORTENKIRCHNER E AND SARICIFTCI NS. 2016. Electrochemical Reduction of Carbon Dioxide to Methanol by Direct Injection of Electrons into Immobilized Enzymes on a Modified Electrode. ChemSusChem 9: 631-635.

SHARMA A, QIANG Y, MEYER AD, KORNACKI P AND PASZCYNSKI A. 2007. Dramatic Increase in Stability and Longevity of Enzymes Attached to Monodispersive Iron Nanoparticles. IEEE Trans Magn 43: 2418-2420.

SHEN J, KORTLEVER R, KAS R, BIRDJA YY, DIAZMORALES O, KWON Y, LEDEZMA-YANEZ I, SCHOUTEN KHP, MUL G AND KOPER TM. 2015. Electrocatalytic reduction of carbon dioxide to carbon monoxide and methane at an immobilized cobalt protoporphyrin. Nat Commun 6: 8177.

SHI JF, JIANG YJ, JIANG ZY, WANG XY, WANG XL, ZHANG SH, HAN PP AND YANG C. 2015. Enzymatic conversion of carbon dioxide. Chem Soc Rev 44: 59816000.

SINGH RK, NAM DH, SINGH R, LEDD JK AND PARK CB. 2017. Photoelectrochemical Reduction of Carbon Dioxide to Methanol through a Highly Efficient Enzyme Cascade. Angew Chem Int Ed 56: 3827-3830.

SMITH E AND MOROWITZ HJ. 2016. The Origin and Nature of Life on Earth: The Emergence of the Fourth Geosphere. Cambridge University Press, Cambridge.

SULTANA S, SAHOO PC, MARTHA S AND PARIDA K. 2016. A review of harvesting clean fuels from enzymatic CO2 reduction. RSC Adv 6: 44170-44194.

SUN Q, JIANG Y, JIANG Z, ZHANG L, SUN X AND LI J. 2009. Green and Efficient Conversion of $\mathrm{CO} 2$ to Methanol by Biomimetic Coimmobilization of Three Dehydrogenases in Protamine-Templated Titania. Ind Eng Chem Res 48: 4210-4215.

TENG S, BEARD K, POURAHMAD J, MORIDANI M, EASSON E, POON R AND O'BRIEN PJ. 2001. The formaldehyde metabolic detoxification enzyme systems and molecular cytotoxic mechanism in isolated rat hepatocytes. Chemico-Biological Interactions 130-132: 285-296.

THOMA JA AND KOSHLAND DE. 1960. Competitive Inhibition by Substrate during Enzyme Action. Evidence for the Induced-fit Theory. J Am Chem Soc 82: 3329-3333.

TOMA HE. 2013. Developing nanotechnological strategies for green industrial processes. Pure Appl Chem 85: 1655 1669.

TOMA HE. 2015. Magnetic nanohydrometallurgy, a nanotechnological approach to elemental sustainability, Green Chem 17: 2017-2041.

VALDÉS-SOLIS TA, REBOLLEDO AF, SEVILLA M, VALLE-VIGÓN P, BOMATI-MIGUEL O, FUERTES AB 
AND TARTAJ P. 2009. Preparation, Characterization, and Enzyme Immobilization Capacities of Superparamagnetic Silica/Iron Oxide Nanocomposites with Mesostructured Porosity. Chem Mater 21: 1806-1814.

WANG F, GUO C, LIU HZ, AND LIU CZ. 2007. Reversible immobilization of glucoamylase by metal affinity adsorption on magnetic chelator particles. J Mol Cat B Enzym 48: 1-5.

WU H, HUANG S AND JIANG Z. 2004. Effects of modification of silica gel and ADH on enzyme activity for enzymatic conversion of $\mathrm{CO} 2$ to methanol. Catalysis Today 98: 545-552.
WU SC AND LIA YK. 2008. Application of bacterial cellulose pellets in enzyme immobilization. J Mol Catalysis B Enzym 54: 103-108.

XU SW, LU Y, LI J, JIANG ZY AND WU H. 2006. Efficient Conversion of $\mathrm{CO} 2$ to Methanol Catalyzed by Three Dehydrogenases Co-encapsulated in an Alginate-Silica (ALG-SiO2) Hybrid Gel. Ind Eng Chem Res 45: 4567-4571.

YON J, PERAHIA D AND GHELIS C. 1998. Conformational dynamics and enzyme activity. Biochimie 80: 33-42

ZENG L, LUO K AND GONG Y. 2006. Preparation and characterization of dendritic composite magnetic particles as a novel enzyme immobilization carrier. J Mol Cat B Enzym 38: 24-28. 